Western University

Scholarship@Western

Biology Publications

Biology Department

5-1-2016

\title{
Paradoxical acclimation responses in the thermal performance of insect immunity.
}

Laura V Ferguson

David E Heinrichs

Brent J Sinclair

Follow this and additional works at: https://ir.lib.uwo.ca/biologypub

Part of the Biology Commons

Citation of this paper:

Ferguson, Laura V; Heinrichs, David E; and Sinclair, Brent J, "Paradoxical acclimation responses in the thermal performance of insect immunity." (2016). Biology Publications. 93.

https://ir.lib.uwo.ca/biologypub/93 
1 Paradoxical acclimation responses in the thermal performance of insect immunity

2

3 Laura V.Ferguson ${ }^{1 *}$, David E. Heinrichs ${ }^{2}$, Brent J. Sinclair ${ }^{1}$

4

$5 \quad{ }^{1}$ Department of Biology, University of Western Ontario, London, ON, Canada N6A 5B7

6

$7 \quad{ }^{2}$ Department of Microbiology and Immunology, University of Western Ontario, London, ON,

8 Canada N6A 5B7

$9 *$ Author for correspondence: 1fergus9@uwo.ca

11 Department of Biology, University of Western Ontario, 1151 Richmond Street N, London, ON,

12 Canada N6A 5B7. Phone: 1-519-661-2111 ext. 89158. Fax: 1-519-661-3935 authenticated version is available online at: http://dx.doi.org/[10.1007/s00442-015-3529-6]".

This work is part of Ferguson's PhD, integrating ecophysiology, thermal biology, and ecoimmunology. We measured insect immune performance across temperatures, finding that thermal performance does not consistently respond to acclimation among, or even within, physiological systems. Paradoxically, cold acclimation decreases low temperature immune performance, revealing that cold tolerance trades off with immunity in the cold. Thus, physiological systems differ in their responses to temperature, and conclusions about the impacts of climate change cannot be based on a single performance measure. study and drafting of the manuscript. All authors gave final approval for publication. 


\section{Abstract}

34 Winter is accompanied by multiple stressors, and the interactions between cold and pathogen

35 stress potentially determine the overwintering success of insects. Thus, it is necessary to explore

36 the thermal performance of the insect immune system. We cold-acclimated spring field crickets,

37 Gryllus veletis, to $6^{\circ} \mathrm{C}$ for $7 \mathrm{~d}$ and measured the thermal performance of potential (lysozyme and

38 phenoloxidase activity) and realised (bacterial clearance and melanisation) immune responses.

39 Cold acclimation decreased the critical thermal minimum from $-0.5 \pm 0.25^{\circ} \mathrm{C}$ to $-2.1 \pm 0.18^{\circ} \mathrm{C}$,

40 and chill coma recovery time after $72 \mathrm{~h}$ at $-2^{\circ} \mathrm{C}$ from $16.8 \pm 4.9 \mathrm{~min}$ to $5.2 \pm 2.0 \mathrm{~min}$. Measures

41 of both potential and realised immunity followed a typical thermal performance curve,

42 decreasing with decreasing temperature. However, cold acclimation further decreased realised

43 immunity at low, but not high, temperatures; effectively, activity became paradoxically

44 specialised to higher temperatures. Thus, cold acclimation induced mismatched thermal

45 responses between locomotor and immune systems, as well as within the immune system itself.

46 We conclude that cold acclimation in insects appears to preferentially improve cold tolerance

47 over whole-animal immune performance at low temperatures, and that the differential thermal

48 performance of physiological responses to multiple pressures must be considered when

49 predicting ectotherms' response to climate change.

50

51 Key words: cold, pathogen, thermal performance curve, biotic stressor, plasticity 


\section{Introduction}

Ectotherms can respond to seasonal changes by maintaining homeostasis via phenotypic

54 or developmental plasticity. In insects, the cues that govern acclimation (in the laboratory) or

55 acclimatisation (in the field), such as temperature or photoperiod, often coordinate diverse

56 physiological adjustments to suit a new set of environmental conditions (Harrison et al. 2012).

57 For example, cold-acclimation of the beetle Dendroides canadensis elicits antifreeze protein

58 synthesis, removal of ice nucleators (Olsen and Duman 1997), and modification of epicuticular

59 waxes (Olsen et al. 1998) - all of which contribute to improved cold tolerance. In addition to

60 cold, there are multiple abiotic and biotic stressors associated with winter (Williams et al. 2015),

61 and these can select for thermal plasticity in multiple physiological systems. For instance, cold-

62 acclimation often increases desiccation resistance in insects, likely because of the high water

63 vapour deficits experienced during overwintering (Sinclair et al. 2013; Terblanche et al. 2005).

64 Biotic stressors, such as pathogens, are also likely to affect the success of insects at low

65 temperatures (Hokkanen 1992; Riedel and Steenberg 1998; Webberley and Hurst 2002; Williams

66 et al. 2015), yet the ability of insects to manage cold-related pathogen stress, and the role of

67 phenotypic plasticity in this response, is unclear.

68 Some insect pathogens are cold-active [e.g. fungi in the genera Beauveria and

69 Metarhizium (Fernandes et al. 2008)], or have increased virulence at low temperatures [e.g. the

70 bacterium Yersinia entercolitica (Bresolin et al. 2006)]; thus there is capacity for these cold-

71 adapted pathogens to contribute to mortality of insects at low temperatures (Hokkanen 1992;

72 Steenberg et al. 1995). However, cold exposure appears to upregulate the insect immune system,

73 which may allow insects to respond to cold-associated pathogen stress (Sinclair et al. 2013). For

74 example, cold exposure increases fungal resistance in Pyrrharctia isabella caterpillars (Marshall 
75 and Sinclair 2011) and adult Drosophila melanogaster (Le Bourg et al. 2009), and upregulates

76 genes encoding antimicrobial peptides in both D. melanogaster (Zhang et al. 2011) and the

77 solitary bee Megachile rotundata (Xu and James 2012). Further, this increased immunity appears

78 to translate into fitness: water striders (Aquarias najas) with stronger immune responses have

79 higher overwinter survival (Krams et al. 2011). Although cold-induced upregulation of immunity

80 may be a non-adaptive by-product of responses to cold (Fedorka et al. 2013; Sinclair et al. 2013),

81 the potential for conflicts between the energetic costs of immune responses (Ardia et al. 2012;

82 Freitak et al. 2003; Schmid-Hempel 2003) and energy conservation in the cold (Sinclair, in press)

83 instead suggest that the immune system is upregulated as an adaptive response to low-

84 temperature pathogen pressure (Irwin and Lee 2003; Sinclair, in press ; Williams et al. 2012).

85 However, most studies have been performed upon re-warming from cold exposure, and do not

86 necessarily reflect immune activity at low temperatures. Thus, to determine the ability of insects

87 to combat low-temperature pathogen stress, we must first explore the low-temperature

88 performance of the immune system, as well as the role of acclimation in shaping this

89 performance.

90 We expect the insect immune system to have reduced performance in the cold because it

91 relies on cellular and enzymatic processes that are likely temperature-sensitive (Collazos et al.

92 1994; Le Morvan et al. 1998; Marnila et al. 1995; Somero 1995). Indeed, phagocytosis and

93 encapsulation decrease at $4{ }^{\circ} \mathrm{C}$ in diapausing pupae of the giant silk moth, Samia cynthia pryeri,

94 although some immune function is maintained (Nakamura et al. 2011). However, this loss of

95 performance has the potential to be mitigated through phenotypic plasticity, including the

96 expression of cold-active isoforms of immune-related enzymes, or an increase in the

97 concentration of cells and molecules necessary for an immune response (Angilletta 2009; 
98 Somero 1995). In either case, if there is an adaptive advantage to improved immunity at low

99 temperatures, then cold-acclimation would be expected to modify the thermal performance of the

100 immune system to increase activity at low temperatures (Angilletta 2009).

101 Thus, to understand the potential interactions of cold and immune stress in insects, and to

102 understand the role of biotic interactions in shaping ectotherm performance in a changing

103 climate, it is necessary to explore the thermal biology of the insect immune system. We explored

104 the thermal sensitivity and plasticity of the insect immune system by measuring the thermal

105 performance of immune-related enzymes in vitro, and immune responses in vivo [i.e. potential

106 immunity and realised immunity, respectively (Fedorka et al. 2007; Gershman 2008)] in warm-

107 and cold-acclimated spring field crickets (Gryllus veletis). We used a short-term acclimation to

108 explore the possibility of thermal plasticity in the immune system, as a first step in understanding

109 how the thermal biology of the immune system might impact the ecology of overwintering

110 insects. Cold acclimation differentially affected realised and potential immunity, in a direction

111 that is not predicted by the whole-organism response to cold acclimation. We suggest that

112 pathogen stress may be most prevalent upon re-warming from cold, and conclude that divergent

113 thermal performance of distinct stress responses must be considered when predicting ectotherms'

114 responses to climate change.

\section{Material and Methods}

117 We studied the thermal biology of the immune system in the spring field cricket, Gryllus

118 veletis. Gryllus veletis overwinters as a late-instar nymph in temperate North America

119 (Alexander 1968), and has a cold acclimation response (Coello Alvarado et al. 2015). Our

120 cricket colony was derived from a population collected in Lethbridge, Alberta, in 2010, and were 
121 reared from egg to nymph at $25^{\circ} \mathrm{C}(14 \mathrm{~L}: 10 \mathrm{D})$ as described by Coello Alvarado et al. (2015).

122 We haphazardly assigned female 6th instar nymphs (the overwintering stage) into individual 180 123 mL clear plastic cups and provided ad libitum rabbit chow (Little Friends Rabbit Food, Martin

124 Mills, Elmira, ON, Canada) and water, with cardboard shelters. We cold-acclimated (CA)

125 individuals at $6{ }^{\circ} \mathrm{C}$ on a short light cycle (10 L: $\left.14 \mathrm{D}\right)$ or maintained them at rearing conditions 126 (warm-acclimated, WA) for $7 \mathrm{~d}$.

128 Thermal limits of locomotor activity

129 We measured the critical thermal minimum $\left(\mathrm{CT}_{\min }\right.$, the temperature at which an insect 130 enters chill coma) following MacMillan and Sinclair (2011), and chill-coma recovery (CCR) time 131 following MacMillan et al. (2012). Briefly, we cooled crickets at $0.25{ }^{\circ} \mathrm{C} / \mathrm{min}$ from $22{ }^{\circ} \mathrm{C}$ to the 132 temperature at which movement ceased. Similarly, we measured the critical thermal maximum $133\left(\mathrm{CT}_{\max }\right)$ by increasing temperature at $0.25{ }^{\circ} \mathrm{C} / \mathrm{min}$ from $22{ }^{\circ} \mathrm{C}$ until we visually observed the 134 onset of spasms (Lutterschmidt and Hutchison 1997). For CCR, we cooled crickets at 0.25 $135{ }^{\circ} \mathrm{C} / \mathrm{min}$ from $22{ }^{\circ} \mathrm{C}$ to $-2{ }^{\circ} \mathrm{C}$ and held them at $-2{ }^{\circ} \mathrm{C}$ for $72 \mathrm{~h}$. Crickets were returned to room 136 temperature and we recorded the time taken to achieve a coordinated righting response.

\section{Potential Immune Response}

We collected haemolymph for measuring potential humoral immunity following Adamo

140 (2004), and all measurements of potential immunity at different temperatures were tested on

141 extracted hemolymph. We pierced the membrane under the pronotum and collected $2 \mu \mathrm{L}$ of

142 haemolymph with a micropipette. We mixed $2 \mu \mathrm{L}$ of haemolymph with either $2 \mu \mathrm{L}$ of

143 anticoagulant buffer $(98 \mathrm{mM} \mathrm{NaOH}, 186 \mathrm{mM} \mathrm{NaCl}, 1.7 \mathrm{mM}$ EDTA, $41 \mathrm{mM}$ citric acid, pH 6.8; 
144 for lysozyme activity) or $50 \mu \mathrm{L}$ of phosphate-buffered saline [PBS; for phenoloxidase (PO)

145 activity] and snap-froze it in liquid nitrogen, followed by storage at $-80^{\circ} \mathrm{C}$.

To estimate the bactericidal activity of lysozyme, we followed Vilcinskas and Matha

147 (1997), with some modifications. We added $4 \mu \mathrm{L}$ of the haemolymph-anticoagulant-buffer

148 suspension to $2 \mathrm{~mm}$ diameter wells on a petri plate containing Micrococcus lysodeikticus (luteus)

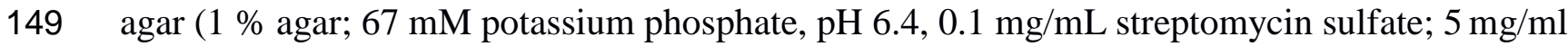

150 M. lysodeikticus). Plates were sealed with Parafilm ${ }^{\circledR}$ and incubated at one of $0,6,12,18,25$ or 30

$151{ }^{\circ} \mathrm{C}$ (MIR-153 incubators, Sanyo Scientific, Bensenville, IL, US).We then measured the area of

152 the cleared region around each well 24 and $48 \mathrm{~h}$ later using NIS Elements Imaging Software

153 (Nikon Instruments Inc, Melville, NY, USA).

154 Total PO activity, which indicates a potential broad-spectrum immune response, was

155 measured spectrophotometrically (Adamo 2004). Briefly, we mixed $25 \mu \mathrm{L}$ of thawed

156 hemoymph/PBS mixture with $70 \mu \mathrm{L}$ alpha-chymotrypsin $(1.3 \mathrm{mg} / \mathrm{mL}$ in PBS $)$ and incubated it

157 for $20 \mathrm{~min}$ at room temperature $\left(22^{\circ} \mathrm{C}\right)$ before adding it to $0.9 \mathrm{~mL}$ of L-DOPA ( $4 \mathrm{mg} / \mathrm{mLin}$

158 PBS). The rate of increase in absorbance was measured over 60 min at one of $6,12,18,25$, or 30

$159{ }^{\circ} \mathrm{C}$ (Carey 100 Spectrophotometer with Peltier-effect Temperature Controller, Agilent, Santa

160 Clara, CA, USA).

161 Higher haemolymph protein concentration is linked to stronger immune responses in 162 insects, especially the melanisation response (Adamo 2004). To measure haemolymph protein 163 concentration, we followed methods as described by Adamo (2004) with some modifications.

164 Briefly, we used $10 \mu \mathrm{L}$ of the haemolymph/PBS mixture in a Bicinchoninic Acid kit (BCA; Life

165 Technologies, Carlsbad, CA, USA) and measured absorbance at $562 \mathrm{~nm}$ in a microplate

166 spectrophotometer (SpectraMax, Molecular Devices, Sunnyvale, CA, USA). We then converted 
absorbance to concentration values using a standard curve created from bovine serum albumin.

\section{Realised Immune Response}

As an estimate of a broad-spectrum, realised immune response, we measured

171 melanisation by inserting a $2 \mathrm{~mm}$ piece of nylon filament (Krams et al. 2011) under the

172 pronotum and placing crickets at $0,6,12,18,25$ or $30^{\circ} \mathrm{C}$ for $12 \mathrm{~h}$. We removed the filament

173 after $12 \mathrm{~h}$, photographed it from two different angles at 30× magnification using a Nikon DSFI

174 camera (Nikon Instruments Inc. Melville, NY, USA) attached to a stereomicroscope, and 175 determined the darkness of each filament using the average grey value calculated in ImageJ

176 (Rasband 1997-2014). We calculated relative melanisation as 255 - the grey value, such that a

177 higher number indicates more melanisation.

178 We measured the in vivo ability of crickets to clear Staphylococcus aureus (strain

179 Newman with chromosomally-encoded tetracycline resistance) from haemolymph following 180 (Haine et al. 2008). Briefly, we diluted S. aureus (grown overnight at $37^{\circ} \mathrm{C}$ in tryptic soy broth) 181 to $1 \times 10^{9} \mathrm{CFU} / \mathrm{mL}$ in PBS and injected $2 \mu \mathrm{L}$ of suspension into the thorax under the pronotum 182 (Adamo 2004) via a $30 \mathrm{G}$ needle. Following $24 \mathrm{~h}$ post-challenge at $0.5,4,12,18,25$, or $30^{\circ} \mathrm{C}$, 183 we homogenised whole crickets in $900 \mu \mathrm{L}$ of PBS to ensure that we captured all remaining

184 bacteria (including those associated with tissue). We diluted and spotted of the homogenate on 185 tryptic soy agar (TSA) containing $2 \mu \mathrm{g} / \mathrm{mL}$ tetracycline and averaged the number of CFU over 186 four replicate spots, following $24 \mathrm{~h}$ at $37^{\circ} \mathrm{C}$. We homogenised a subset of crickets $1 \mathrm{~min}$ 187 following injection to obtain the true number of CFU injected and calculate percent clearance

188 (Haine et al. 2008). Control crickets injected with sterile PBS did not demonstrate any bacterial 189 growth on TSA containing tetracycline. 


\section{Statistical analyses}

192 All analyses were performed in R v3.1.2 (Team 2010) and preliminary data exploration was 193 conducted according to (Zuur et al. 2010). We compared $\mathrm{CT}_{\min }, \mathrm{CT}_{\max }, \mathrm{CCR}$, and protein 194 concentration between CA and WA crickets using Welch's two-sample t-test. We compared the 195 performance curves of immune activity between WA and CA crickets using ANOVA (Angilletta 196 2006). Where necessary, response variables were square-root- (lysozyme, phenoloxidase), 197 arcsine- (bacterial clearance), or log-transformed (melanisation) to satisfy the assumptions of the 198 ANOVA. We assessed the assumptions of ANOVA by plotting residuals against fitted values to 199 confirm homogeneity of variance, and standardised residuals against theoretical quantiles to 200 assess normality (Crawley 2007). We used polynomial contrasts (Lenth 2013) to compare means 201 between warm and cold-acclimated crickets at each temperature.

\section{Results}

204

\section{Thermal limits of locomotor activity}

Cold-acclimation enhanced low temperature locomotor activity of G. veletis and

207 shortened recovery time after cold exposure. The $\mathrm{CT}_{\min }$ of WA crickets was significantly higher 208 than that of CA crickets $\left(\mathrm{t}_{14.46}=5.53, \mathrm{p}<0.001\right.$; Fig. 1A); however, there was no difference 209 between the $\mathrm{CT}_{\max }$ of WA and CA crickets (Fig. 1B; $\mathrm{t}_{5}=0.11, \mathrm{p}=0.45$ ). Chill comarecovery 210 time was lower in CA crickets than WA crickets (Fig. 1C; $\mathrm{t}_{5.34}=2.19, \mathrm{p}=0.04$ ).

\section{Potential Immune Response}

213 Potential humoral immunity was sensitive to temperature but remained unaffected by acclimation 
214 (Table 1). Specifically, both lysozyme and phenoloxidase activities decreased with decreasing

215 temperature in both WA and CAcrickets (Fig. 2); however, there was no overall difference in the

216 activity of either enzyme in WA compared to CA crickets (Table 1). Haemolymph protein

217 concentration of CA and WA crickets did not differ significantly $\left(\mathrm{t}_{22}=0.59, \mathrm{p}=0.28\right)$.

218

\section{Realised Immune Response}

Temperature also significantly affected realised immunity, including both bacterial

221 clearance and melanisation (Table 1). In addition, and in contrast to potential immunity,

222 acclimation had a significant effect on realised immunity (Table 1). Specifically, melanisation

223 and bacterial clearance were decreased in CA crickets at low temperatures, but largely

224 unchanged at warm temperatures (Fig. 3).

225

\section{Discussion}

We explored the capacity for cold-acclimation of the immune system in G. veletis using 228 an acclimation regime that improved locomotor activity at low temperatures [decreased $\mathrm{CT}_{\min }$ 229 and CCR, recognised proxies for cold tolerance in insects (Andersen et al. 2015)], but had no 230 effect on heat tolerance $\left(\mathrm{CT}_{\max }\right)$. Cold acclimation did not affect potential immunity nor realised

231 immunity at higher temperatures; however, realised immunity decreased in the cold in CA

232 crickets. We suggest that decreased activity in the cold may result from trade-off between some 233 components of immune activity and other physiological responses initiated by cold acclimation. Theory suggests three ways by which the thermal performance of immunity could shift in

235 response to acclimation, if increased low temperature performance were important in the cold: 1) 236 a shift in the thermal performance curve (TPC) where $\mathrm{T}_{\mathrm{opt}}$ decreases (i.e. beneficial acclimation; 
237 Fig. 4A); 2) a shift in the TPC where $\mathrm{T}_{\text {opt }}$ is unchanged but maximal activity is higher across all 238 temperatures (i.e. colder is better; Fig. 4B); or 3) a reduction in thermal sensitivity, whereby the 239 TPC encompasses a larger range of activity, but maximal activity at the $\mathrm{T}_{\text {opt }}$ is lower [i.e.

240 generalist vs. specialist; Fig. 4C (Angilletta 2009)]. However, we found that cold-acclimation

241 resulted in a paradoxical narrowing of the TPC of realised immune responses in crickets,

242 whereby activity was specialised to higher instead of lower temperatures, and the $\mathrm{T}_{\text {opt }}$ and

243 maximal activity at the $\mathrm{T}_{\mathrm{opt}}$ were unaffected (Fig. 3, 4D). Decreased performance in the cold may

244 result from trade-offs between the increased energy demands of improving cold tolerance (e.g.

245 production of cryoprotectants) and the immune system (Sinclair, in press). For example,

246 infection decreases CCR time in Drosophila melanogaster (Linderman et al. 2012), suggesting

247 that immune activity conflicts with cold tolerance. Thus, cold acclimation may preferentially

248 improve cold tolerance over whole-animal immune performance at low temperatures.

249 In addition to a decrease in realised immunity, cold acclimation produced mismatches

250 between potential and realised immunity. First, acclimation appeared only to decrease realised

251 immune responses in the cold, while potential immunity remained unchanged. Realised immune

252 responses, such as bacterial clearance, are generally mediated by the combined activity of

253 haemocytes, enzymes, and antimicrobial peptides (Gillespie and Kanost 1997), while the

254 potential immunity that we measured focused on the activity enzymes in isolation. Decreased

255 realised immune responses that are not paralleled in potential responses suggest that cold

256 acclimation has a stronger effect on cellular activity than it does on the activity of enzymes or

257 antimicrobial peptides, although we caution that we did not measure all components of the

258 immune system. Differences in potential and realised immune activity can create a disparate

259 estimate of overall immunocompetence (Fedorka et al. 2007), yet also hint at the relative 
260 contributions of different immune components to protection against pathogens. In this case,

261 overall immunocompetence may decrease in the cold (realised immunity), yet a basal level of

262 protection may persist through the activity of enzymes and antimicrobial peptides (potential

263 immunity). We suggest that measuring multiple components of the immune system provides a

264 more comprehensive picture of the effects of thermal acclimation on immune performance, and

265 that both potential and realised responses should be considered when assessing the impact of the 266 abiotic environment on immunity.

267 Second, although PO activity and melanisation are linked as an immune response

268 (González-Santoyo and Córdoba-Aguilar 2012) their thermal optima were disparate; PO activity

269 peaked at $25^{\circ} \mathrm{C}$, whereas melanisation peaked at $18{ }^{\circ} \mathrm{C}$, in both $\mathrm{CA}$ and WA crickets [similar to

270 phagocytic capacity in mosquitoes (Murdock et al. 2012)]. The lower $\mathrm{T}_{\mathrm{opt}}$ of melanisation

271 compared to that of $\mathrm{PO}$ activity appears to reflect a disconnect between the $\mathrm{T}_{\mathrm{opt}}$, or thermal

272 sensitivity, of different components of the overall melanisation response. Temperature is likely to

273 drive the local adaptation of hosts and pathogens (Sternberg and Thomas 2014) and may have

274 driven the selection of G. veletis immune performance to a thermal optimum lower than enzyme

275 activity would predict. Thus, using thermal performance curves, we may gain insight into the

276 evolution of thermal sensitivity and plasticity of immune activity, and can begin to predict the

277 capacity for hosts to respond to pathogens under climate change scenarios.

278 Pathogen growth generally increases as temperatures increase (Harvell et al. 2002); thus,

279 re-warming from cold exposure is likely to lead to an increase in pathogen pressure, and require

280 an increase in immune activity. Despite decreased immune activity in the cold, realised immune

281 activity in CA crickets was maintained at optimal temperatures, which suggests that immune

282 activity may be required following, but not during, cold exposure. Seasonal immune activity in 
283 other ectotherms, including fish [e.g. Sparus aurata (Tort et al. 1998)] and frogs [e.g. Rana

284 pipiens (Maniero and Carey 1997)], follows a pattern that reflects the effects of a short-term

285 acclimation on immune activity in crickets; specifically, immune activity decreases during the

286 winter but rapidly recovers, and even increases beyond control levels, upon re-warming. In

287 hibernators, such as the golden-mantled ground squirrel (Spermophilus lateralus), interbout

288 euthermia is accompanied by an increase in immune activity, thereby allowing the animal to

289 combat pathogens that have established in the cold (Prendergast et al. 2002). The thermal

290 performance of immune activity in G. veletis following a short acclimation to low temperatures

291 may thus reflect a seasonal pattern of immune activity in insects that fluctuates with seasonal

292 shifts in pathogen pressure.

293 The contrast between decreased immune activity in the cold and maintained immune

294 activity at high temperatures suggests that fluctuating temperatures will affect the ability of cold-

295 acclimated insects to fight cold-active pathogens and survive at low temperatures. Transient

296 increases in environmental temperature may facilitate a response to cold-active pathogens by

297 allowing for increased immune activity. For example, the expression of genes encoding immune

298 peptides in $M$. rotundata increases under warming provided by fluctuating thermal regimes

299 (Torson et al. 2015). Conversely, increased immune activity under periods of re-warming is

300 likely to decrease the energy available for responses to other stressors, such as cold. Further,

301 immune activity can trade-off with components of fitness, such as growth (Rantala and Roff

302 2005) and reproduction (Adamo et al. 2001; Ahmed et al. 2002); thus fluctuations in temperature

303 may create conflict between the response to pathogens and fitness- or stress-related physiological

304 processes. If climate change-related warming leads to an increase in both pathogen pressure and

305 immune activity, both transient and seasonal periods of re-warming will affect the interactions 
306 between energy expenditure and pathogen response, thereby contributing to the impacts of cold 307 and winter on insects. We do caution, however, that the acclimation used in our study does not 308 reflect the type of long-term, seasonal acclimation that an insect would experience in preparation 309 for overwintering (Tauber et al. 1986), and thus we are limited in using our results to predict the 310 outcome of insect-pathogen responses in the wild.

311 As global temperatures shift with climate change, it is increasingly important to 312 understand the physiological capacity of organisms to respond to changes in their environment 313 (Araújo and Luoto 2007; Chown et al. 2010). Ecological physiology often quantifies this 314 capacity of ectotherms to respond to environmental change by measuring the thermal sensitivity 315 and plasticity of one trait or system; for example, thermal limits to activity (Terblanche et al. 316 2008) or reproduction (Cudmore et al. 2010). However, multiple abiotic and biotic pressures co317 occur, and we must instead consider what phenotypes are produced by the simultaneous activity 318 of multiple physiological systems in response to these pressures. Increased cold-tolerance, 319 coupled with decreased immune activity at low temperatures in cold-acclimated G. veletis, 320 demonstrates that thermal plasticity was disconnected among and within physiological systems;

321 this suggests that plasticity in one trait does not necessarily reflect the response of the whole 322 organism to connected shifts in its abiotic and biotic environment. Thus, to predict the phenotype 323 of an organism that will succeed under climate change scenarios, we must begin to measure 324 multiple physiological traits that correspond to multiple, integrated pressures in a changing 325 environment.

\section{Conclusions}


We show that cold acclimation improves cold tolerance in G. veletis, does not affect the

329 activity of immune enzymes in vitro (potential immunity), and decreases realised immune

330 activity at low temperatures. Thus, measures of whole-animal immune performance appear to

331 trade-off with cold tolerance, and we suggest that pathogen stress may be more prevalent upon

332 re-warming. Climate change will result in alterations to the interactions among multiple

333 stressors, such as between temperature and pathogens (Todgham and Stillman 2013), and the

334 thermal performance of the responses to these stressors will contribute to success under new

335 environmental conditions. However, we show that thermal performance does not consistently

336 respond to acclimation among - or even within - physiological systems. Therefore we caution

337 against predicting responses to climate change based on thermal performance of a single

338 physiological system.

\section{Acknowledgements}

341 Thanks to Dr. Chris Guglielmo, for equipment access, Benjamin Arsic and Ron Flannagan for

342 microbiological assistance, and Amanda Hu, Steven Villani, Steven Xia, and Joshua Zyss for

343 cricket rearing. We are grateful to Caroline Williams and anonymous reviewers for comments

344 that improved the manuscript. Supported by the Natural Sciences and Engineering Research

345 Council of Canada via a Discovery Grant to BJS and a PGS-D scholarship to LVF; by a grant

346 from the Canadian Foundation for Innovation to BJS; and by a grant from The Canadian

347 Institutes of Health Research to DEH. 
353

354

355

356

357

358

359

360

361

362

363

364

365

366

367

368

369

370

371

372

373

374

375

376

377

378

379

380

381

382

383

384

385

386

387

388

389

390

391

392

393

394

395

396

397

398

399

400

Adamo SA (2004) Estimating disease resistance in insects: phenoloxidase and lysozyme-like activity and disease resistance in the cricket Gryllus texensis. J Insect Physiol 50:209216. doi: 10.1016/j.jinsphys.2003.11.011

Adamo SA, Jensen M, Younger M (2001) Changes in lifetime immunocompetence in male and female Gryllus texensis (formerly G. integer): trade-offs between immunity and reproduction. Animal Behav 62:417-425. doi: 10.1006/anbe.2001.1786

Ahmed AM, Baggott SL, Maingon R, Hurd H (2002) The costs of mounting an immune response are reflected in the reproductive fitness of the mosquito Anopheles gambiae. Oikos 97:371-377

Alexander RD (1968) Life cycle origins, speciation, and related phenomena in crickets. Q Rev Biol 43:1-41

Andersen JL et al. (2015) How to assess Drosophila cold tolerance: chill coma temperature and lower lethal temperature are the best predictors of cold distribution limits. Func Ecol 29:55-65. doi: 10.1111/1365-2435.12310

Angilletta MJ (2006) Estimating and comparing thermal performance curves. J Therm Biol 31:541-545. doi: 10.1016/j.jtherbio.2006.06.002

Angilletta MJ, Jr. (2009) Thermal Adaptation: A Theoretical and Empirical Synthesis. Oxford University Press, New York, United States of America

Araújo MB, Luoto M (2007) The importance of biotic interactions for modelling species distributions under climate change. Global Ecol Biogeograph 16:743-753. doi: 10.1111/j.1466-8238.2007.00359.x

Ardia DR, Gantz JE, BC, Schneider, Strebel S (2012) Costs of immunity in insects: an induced immune response increases metabolic rate and decreases antimicrobial activity. Func Ecol 26:732-739. doi: 10.1111/j.1365-2435.2012.01989.x

Bresolin G, Morgan JA, Ilgen D, Scherer S, Fuchs TM (2006) Low temperature-induced insecticidal activity of Yersinia enterocolitica. Molec Microbiol 59:503-512. doi: 10.1111/j.1365-2958.2005.04916.x

Chown SL, Hoffmann AA, Kristensen TN, Angilletta MJ, Stenseth NC, Pertoldi C (2010) Adapting to climate change: a perspective from evolutionary physiology. Climate Res 43:3-15. doi: 10.3354/cr00879

Coello Alvarado LE, MacMillan HA, Sinclair BJ (2015) Chill-tolerant Gryllus crickets maintain ion balance at low temperatures. J Insect Physiol 77:15-25. doi: 10.1016/j.jinsphys.2015.03.015

Collazos ME, Ortega E, Barriga C (1994) Effect of temperature on the immune system of a cyprinid fish (Tinca tinca, L). Blood phagocyte function at low temperatures. Fish Shellfish Immunol 4:231-238

Crawley MJ (2007) The R Book. John Wiley \& Sons, Ltd, New York

Cudmore TJ, Björklund N, Carroll AL, Staffan Lindgren B (2010) Climate change and range expansion of an aggressive bark beetle: evidence of higher beetle reproduction in naïve host tree populations. J Appl Ecol 47:1036-1043. doi: 10.1111/j.1365-2664.2010.01848.x

Fedorka KM, Copeland EK, Winterhalter WE (2013) Seasonality influences cuticle melanization and immune defense in a cricket: support for a temperature-dependent immune investment hypothesis in insects. J Exp Biol 216:4005-4010. doi: 10.1242/jeb.091538

Fedorka KM, Linder JE, Winterhalter W, Promislow D (2007) Post-mating disparity between potential and realized immune response in Drosophila melanogaster. Proc R Soc B 274:1211-1217. doi: 10.1098/rspb.2006.0394

Fernandes EK, Rangel DE, Moraes AM, Bittencourt VR, Roberts DW (2008) Cold activity of Beauveria and Metarhizium, and thermotolerance of Beauveria. J Invert Pathol 98:69-78. 
401

402

403

404

405

406

407

408

409

410

411

412

413

414

415

416

417

418

419

420

421

422

423

424

425

426

427

428

429

430

431

432

433

434

435

436

437

438

439

440

441

442

443

444

445

446

447

448

449

450

451

doi: 10.1016/j.jip.2007.10.011

Freitak D, Ots I, Vanatoa A, Horak P (2003) Immune response is energetically costly in white cabbage butterfly pupae. Proc R Soc B 270:S220-222. doi: 10.1098/rsbl.2003.0069

Gershman SN (2008) Sex-specific differences in immunological costs of multiple mating in Gryllus vocalis field crickets. Behav Ecol 19:810-815. doi: 10.1093/beheco/arn040

Gillespie JP, Kanost MR (1997) Biological mediators of insect immunity. Ann Rev Entomol 42:611-643

González-Santoyo I, Córdoba-Aguilar A (2012) Phenoloxidase: a key component of the insect immune system. Entomol Exp Appl 142:1-16. doi: 10.1111/j.1570-7458.2011.01187.x

Haine ER, Moret Y, Siva-Jothy MT, Rolff J (2008) Antimicrobial defense and persistent infection in insects. Science 322:1257-1259. doi: 10.1126/science.1165265

Harrison JF, Woods HA, Roberts SP (2012) Ecological and Environmental Physiology of Insects. Oxford University Press, Oxford, New York

Harvell DH et al. (2002) Climate warming and disease risks for terrestrial and marine biota. Science 296:2158-2162

Hokkanen HMT (1992) Overwintering survival and spring emergence in Meligethes aeneus: effects of body weight, crowding, and soil treatment with Beauveria bassiana. Entomol Exp Appl 67:241-246

Irwin JT, Lee RE, Jr. (2003) Cold winter microenvironments conserve energy and improve overwintering survival and potential fecundity of the goldenrod gall fly, Eurosta solidaginis. Oikos 100:71-78

Krams I, Daukšte J, Kivleniece I, Krama T, Rantala MJ (2011) Overwinter survival depends on immune defence and body length in male Aquarius najas water striders. Entomol Exp Appl 140:45-51. doi: 10.1111/j.1570-7458.2011.01132.x

Le Bourg E, Massou I, Gobert V (2009) Cold stress increases resistance to fungal infection throughout life in Drosophila melanogaster. Biogerontol 10:613-625. doi: 10.1007/s10522-008-9206-y

Le Morvan C, Troutaud D, Deschaux P (1998) Differential effects of temperature on specific and nonspecific immune defences in fish. J Exp Biol 201:165-168

Lenth RV (2013) Ismeans: Least-Squares means, R package version 1.06-05 edn

Linderman JA, Chambers MC, Gupta AS, Schneider DS (2012) Infection-related declines in chill coma recovery and negative geotaxis in Drosophila melanogaster. PloS one 7:e41907. doi: 10.1371/journal.pone.0041907

Lutterschmidt WI, Hutchison VH (1997) The critical thermal maximum: data to support the onset of spasms as the definitive end point. Can J Zool 75:1530-1556

MacMillan HA, Sinclair BJ (2011) The role of the gut in insect chilling injury: cold-induced disruption of osmoregulation in the fall field cricket, Gryllus pennsylvanicus. J Exp Biol 214:726-734. doi: 10.1242/jeb.051540

MacMillan HA, Williams CM, Staples JF, Sinclair BJ (2012) Reestablishment of ion homeostasis during chill-coma recovery in the cricket Gryllus pennsylvanicus. PNAS 109:2075020755

Maniero GD, Carey C (1997) Changes in selected aspects of immune function in the leopard frog, Rana pipiens, associated with exposure to cold. J Comp Physiol B167:256-263

Marnila P, Tiiska A, Lagerspetz K, Lilius E-M (1995) Phagocyte activity in the frog Rana temporaria: whole blood chemiluminescence method and the effects of temperature and thermal acclimation. Comp Biochem Physiol 111A:609-614

Marshall KE, Sinclair BJ (2011) The sub-lethal effects of repeated freezing in the woolly bear caterpillar Pyrrharctia isabella. J Exp Biol 214:1205-1212. doi: 10.1242/jeb.054569

Murdock CC, Paaijmans KP, Bell AS, King JG, Hillyer JF, Read AF, Thomas MB (2012) Complex effects of temperature on mosquito immune function. Proc R Soc B 279:3357-3366. doi: $10.1098 /$ rspb.2012.0638 
Nakamura A et al. (2011) Innate immune system still works at diapause, a physiological state of dormancy in insects. Biochem Biophys Res Comm 410:351-357. doi: 10.1016/j.bbrc.2011.06.015

Olsen TM, Duman JG (1997) Maintenance of the superooled state in overwintering pyrochroid beetle larvae, Dendroides canadensis: role of hemolymph ice nucleators and antifreeze proteins. J Comp Physiol B 167:105-113

Olsen TM, Sass SJ, Li N, Duman JG (1998) Factors contributing to seasonal increases in inoculative freezing resistance in overwintering fire-colored beetle larvae Dendroides canadensis (Pyrochroidae). J Exp Biol 201:1585-1594

Prendergast BJ, Freeman DA, Zucker I, Nelson RJ (2002) Periodic arousal from hibernation is necessary for initiation of immune responses in ground squirrels. Am J Physiol 282:R1054-R1062

Rantala MJ, Roff DA (2005) An analysis of trade-offs in immune function, body size and development time in the Mediterranean Field Cricket, Gryllus bimaculatus. Func Ecol 19:323-330. doi: 10.1111/j.1365-2435.2005.00979.x

Rasband WS (1997-2014) Image J, 1.45S edn. National Institutes of Health, Bethesda, Maryland, USA

Riedel W, Steenberg T (1998) Adult polyphagous coleopterans overwintering in cereal boundaries: winter mortality and susceptibility to the entomopathogenic fungus Beauveria bassiana. BioControl 43:175-188

Schmid-Hempel P (2003) Variation in immune defence as a question of evolutionary ecology. Proc R Soc B 270:357-366. doi: 10.1098/rspb.2002.2265

Sinclair BJ (in press) Linking energetics and overwintering in temperate insects. J Therm Biol doi: 10.1016/j.jtherbio.2014.07.007

Sinclair BJ, Ferguson LV, Salehipour-shirazi G, MacMillan HA (2013) Cross-tolerance and cross-talk in the cold: relating low temperatures to desiccation and immune stress in insects. Int Comp Biol 53:545-556. doi: 10.1093/icb/ict004

Somero GN (1995) Proteins and temperature. Ann Rev Physiol 57:43-68

Steenberg T, Langer V, Esbjerg P (1995) Entomopathogenic fungi in predatory beetles (col.: Carabidae and Staphylinidae) from agricultural fields. Entomophaga 40:77-85

Sternberg ED, Thomas MB (2014) Local adaptation to temperature and the implications for vector-borne diseases. Trends Parasitol 30:115-122. doi: 10.1016/j.pt.2013.12.010

Tauber MJ, Tauber CA, Masaki S (1986) Seasonal Adaptations of Insects. Oxford University Press, New York

Team RDC (2010) R: A language and environment for statistical computing. R Foundation for Statistical Computing, Vienna, Austria

Terblanche JS, Clusella-Trullas S, Deere JA, Chown SL (2008) Thermal tolerance in a southeast African population of the tsetse fly Glossina pallidipes (Diptera, Glossinidae): implications for forecasting climate change impacts. J Insect Physiol 54:114-127. doi: 10.1016/j.jinsphys.2007.08.007

Terblanche JS, Sinclair BJ, Jaco Klok C, McFarlane ML, Chown SL (2005) The effects of acclimation on thermal tolerance, desiccation resistance and metabolic rate in Chirodica chalcoptera (Coleoptera: Chrysomelidae). J Insect Physiol 51:1013-1023. doi: 10.1016/j.jinsphys.2005.04.016

Todgham AE, Stillman JH (2013) Physiological responses to shifts in multiple environmental stressors: relevance in a changing world. Int Comp Biol 53:539-544. doi: 10.1093/icb/ict086

Torson AS, Yocum GD, Rinehart JP, Kemp WP, Bowsher JH (2015) Transcriptional responses to fluctuating thermal regimes underpinning differences in survival in the solitary bee Megachile rotundata.J Exp Biol. doi: 10.1242/jeb.113829

Tort L, Padros F, Rotillant J, Crespo S (1998) Winter syndrome in the gilthead sea bream 
Vilcinskas A, Matha V (1997) Effect of the entomopathogenic fungus Beauveria bassiana on the humoral immune response of Galleria mellonella larvae (Lepidoptera: Pyralidae). Eur J Entomol 94:461-472

Webberley KM, Hurst GDD (2002) The effect of aggregative overwintering on an insect sexually transmitted parasite system. J Parasitol 88:707-712

Williams CM, Henry HA, Sinclair BJ (2015) Cold truths: how winter drives responses of terrestrial organisms to climate change. Biol Rev Camb Philos Soc. doi: 10.1111/brv. 12105

Williams CM, Marshall KE, MacMillan HA, Dzurisin JD, Hellmann JJ, Sinclair BJ (2012) Thermal variability increases the impact of autumnal warming and drives metabolic depression in an overwintering butterfly. PloS one 7:e34470. doi: 10.1371/journal.pone.0034470

$\mathrm{Xu} \mathrm{J}$, James RR (2012) Temperature stress affects the expression of immune response genes in the alfalfa leafcutting bee, Megachile rotundata. Insect Molec Biol 21:269-280. doi: 10.1111/j.1365-2583.2012.01133.x

Zhang J, Marshall KE, Westwood JT, Clark MS, Sinclair BJ (2011) Divergent transcriptomic responses to repeated and single cold exposures in Drosophilamelanogaster. J Exp Biol 214:4021-4029. doi: 10.1242/jeb.059535

Zuur AF, leno EN, Elphick CS (2010) A protocol for data exploration to avoid common statistical problems. Methods Ecol Evol 1:3-14. doi: 10.1111/j.2041-210X.2009.00001.x 


\section{Figures and Tables}

527 Fig. 1 Locomotor activity related to cold tolerance in warm- and cold-acclimated Gryllus veletis.

528 (A) The critical thermal minima, or the temperatures at which crickets entered chill coma $(\mathrm{n}=9$

529 WA, 8 CA). (B) The critical thermal maxima, or temperatures indicating the onset of heat spasms

$530(\mathrm{n}=6 \mathrm{WA}, 5 \mathrm{CA}) .(\mathrm{C})$ Time taken to recover from $72 \mathrm{~h}$ in chill coma at $-2{ }^{\circ} \mathrm{C}(\mathrm{n}=5$ per

531 acclimation)

532

533 Fig. 2 Potential immune activity in warm- and cold-acclimated Gryllus veletis. (A) Lysozyme

534 activity in vitro, measured as the zone of inhibition of Micrococcus luteus from $24 \mathrm{~h}-48 \mathrm{~h}(\mathrm{n}=$

535 6-8 per acclimation, per temperature) (B) Total phenoloxidase activity measured in vitro as an

536 increase in absorbance at $495 \mathrm{~nm}(\mathrm{n}=4-5$ per acclimation, per temperature). Points represent

537 mean \pm SEM

538

539 Fig. 3 Realised immune activity in warm- and cold-acclimated Gryllus veletis. (A) Melanisation,

540 represented as a reverse grey value, of an implanted nylon filament $(n=4-5$ per acclimation, per

541 temperature) (B) The proportion of Staphylococcus aureus cleared from the haemolymph in vivo,

$54224 \mathrm{~h}$ following inoculation $(n=4-8$ per acclimation, per temperature). Points represent mean \pm

543 SEM. Asterisks indicate significant differences between warm- and cold-acclimated crickets, $\mathrm{p}<$

$544 \quad 0.05$

545

546 Fig. 4 Thermal performance curves of the potential outcomes of cold-acclimation on immune

547 activity. A) The Beneficial Acclimation Hypothesis B) The Colder is Better Hypothesis C) The

548 Generalist-Specialist hypothesis D) Paradoxical narrowing of the TPC, representing

549 specialisation of activity to temperatures not predicted by acclimation temperature 
1 Table 1. ANOVA results of the thermal performance of immune activity in warm- and cold2 acclimated Gryllus veletis. Bolded p-values represent significant effects of each term

3 (acclimation or temperature) on the response variable.

\begin{tabular}{|c|c|c|c|c|c|}
\hline \multicolumn{2}{|c|}{ Immune activity } & Term & df & $\mathbf{F}$ & $\mathbf{P}$ \\
\hline \multirow[t]{6}{*}{ Potential } & Lysozyme & Temperature & 5,73 & 36.22 & $<0.01$ \\
\hline & & Acclimation & 1,73 & 0.45 & 0.50 \\
\hline & & Temperature $\times$ Acclimation & 5,73 & 1.24 & 0.30 \\
\hline & Phenoloxidase & Temperature & 4,66 & 27.1 & $<0.01$ \\
\hline & & Acclimation & 1,66 & 0.50 & 0.48 \\
\hline & & Temperature $\times$ Acclimation & 4,66 & 0.34 & 0.85 \\
\hline \multirow[t]{6}{*}{ Realised } & Bacterial clearance & Temperature & 5,55 & 15.49 & $<0.01$ \\
\hline & & Acclimation & 1,55 & 10.45 & $<0.01$ \\
\hline & & Temperature $\times$ Acclimation & 5,55 & 1.31 & 0.27 \\
\hline & Melanisation & Temperature & 5,34 & 9.98 & $<0.01$ \\
\hline & & Acclimation & 1,34 & 30.6 & $<0.01$ \\
\hline & & Temperature $\times$ Acclimation & 5,34 & 2.62 & 0.04 \\
\hline
\end{tabular}



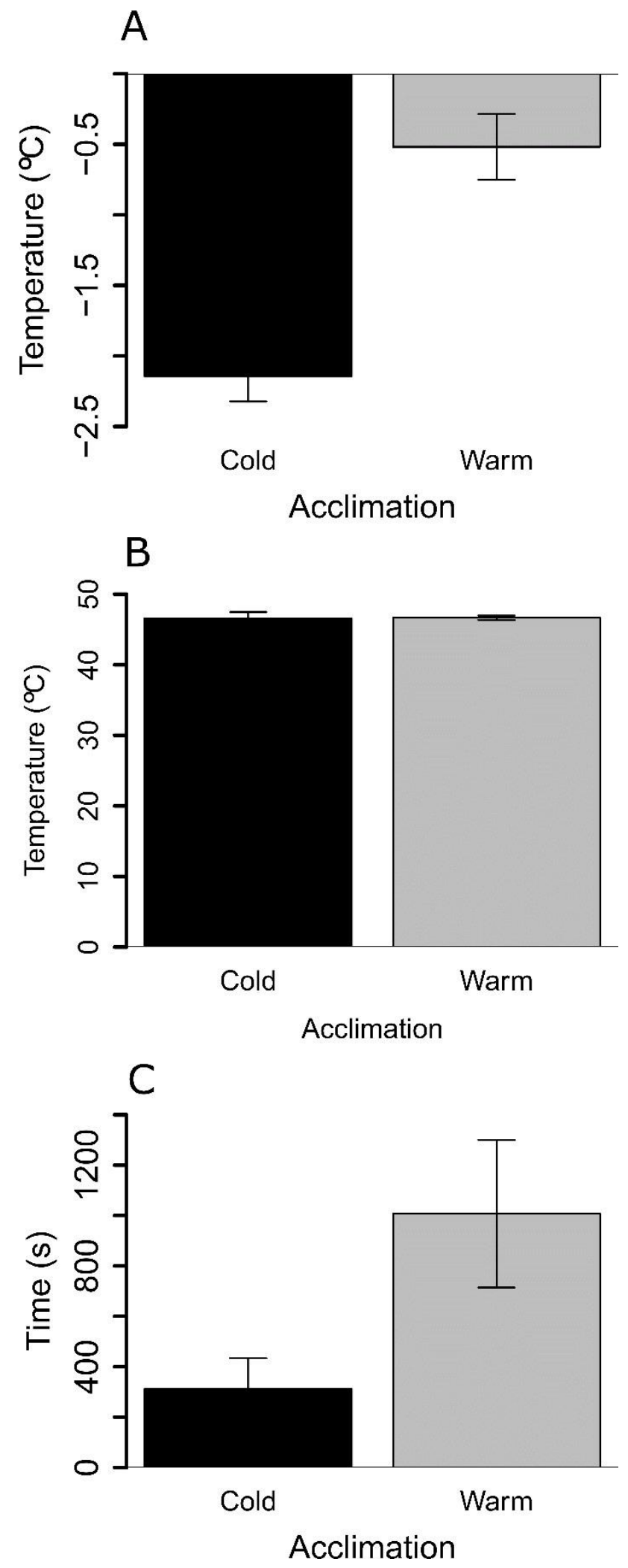

Figure 1. 

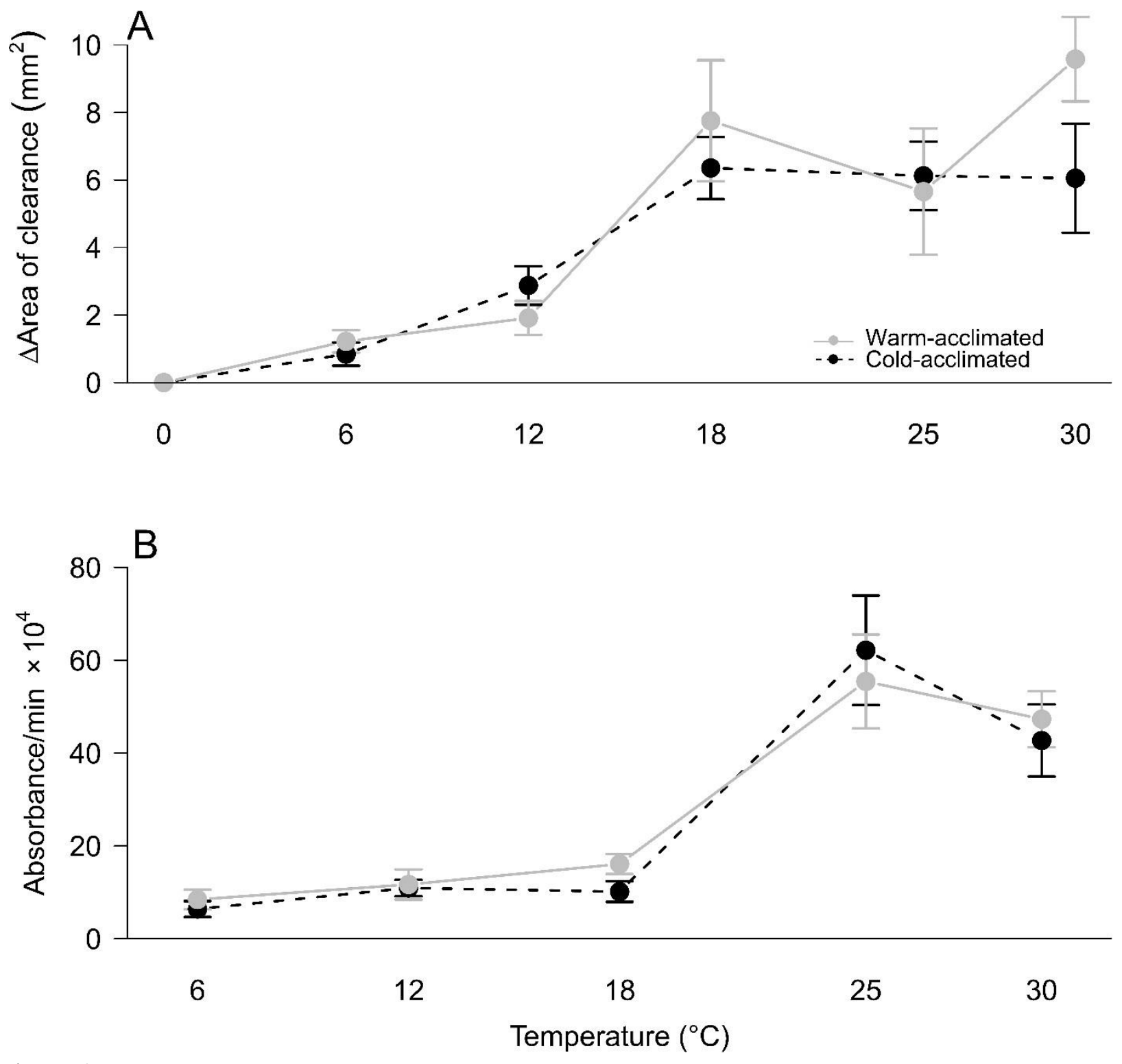

Figure 2. 

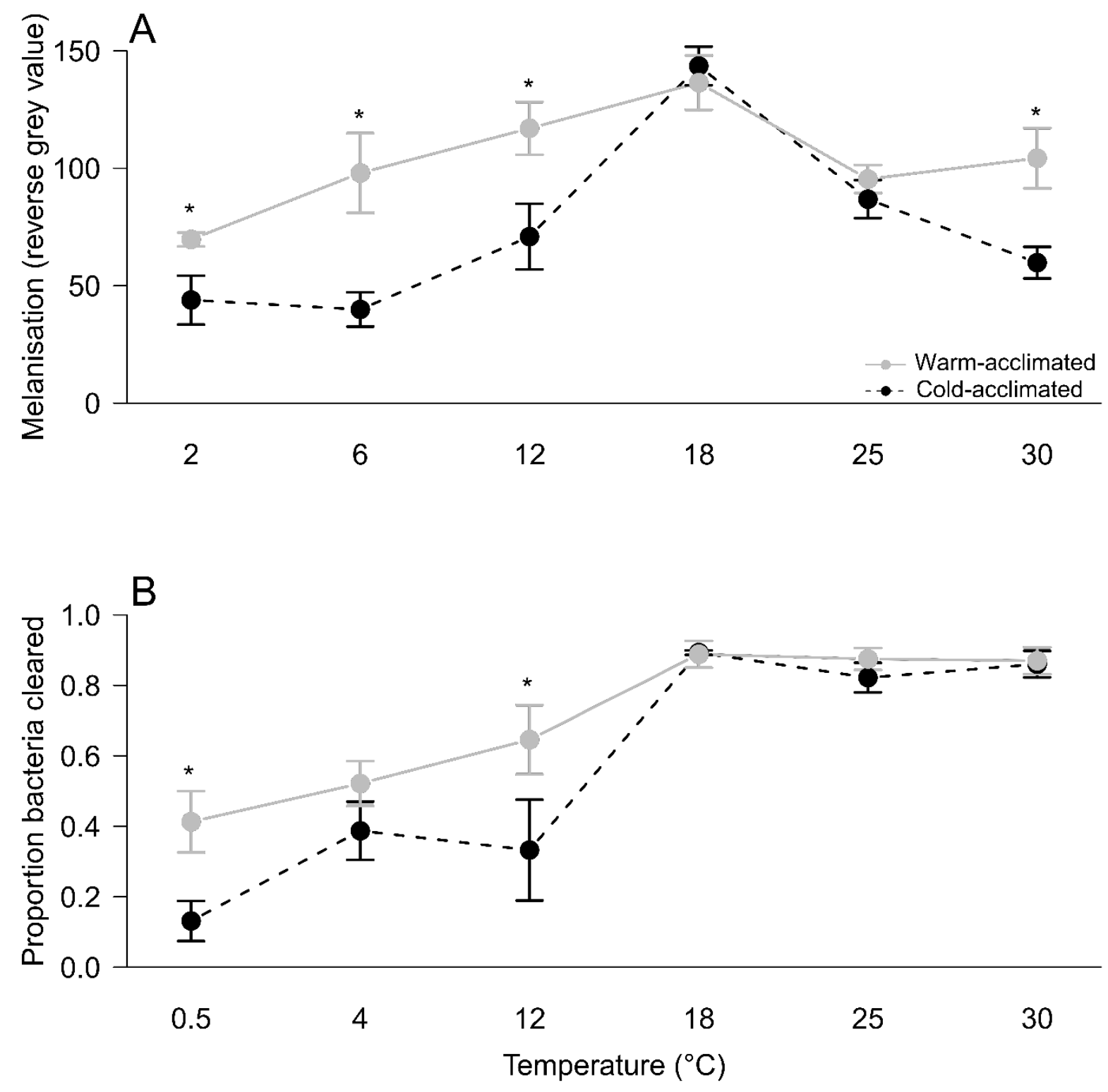

Figure 3. 


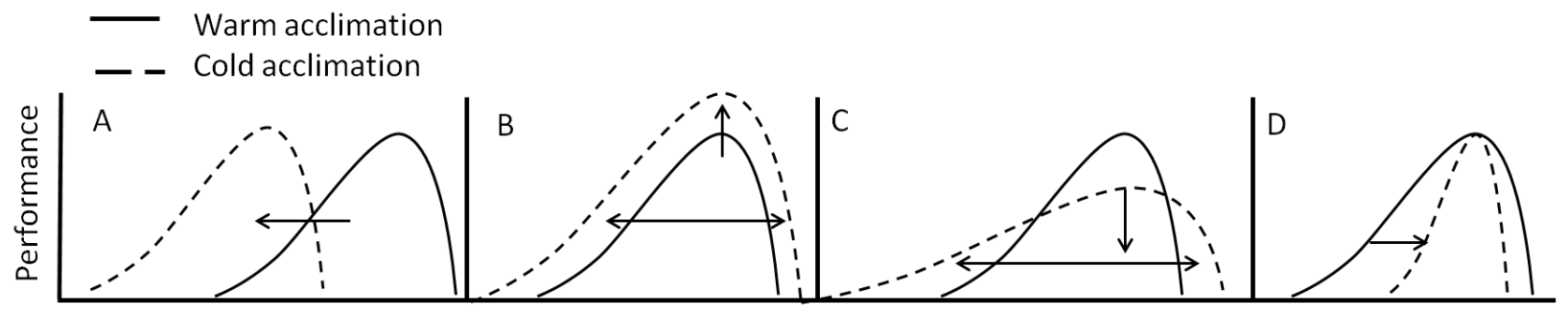

Temperature

Figure 4. 